\title{
Challenges in Translation of Proper Nouns: A Case Study in Persian Translation of George Orwell's Animal Farm
}

\author{
Mojtaba Askari \\ Foreign Languages Faculty, University of Isfahan \\ PO box 81746-73441, Isfahan, Iran \\ Alireza Akbari \\ Foreign Languages Faculty, University of Isfahan \\ PO box 81746-73441, Isfahan, Iran
}

Received: 25-12-2013

doi:10.7575/aiac.ijclts.v.2n.2p.19
Accepted: 30-01- 2014

Published: 01-04-2014

URL: http://dx.doi.org/10.7575/aiac.ijclts.v.2n.2p.19

\begin{abstract}
Nowadays, one of the important problems in translation field will be Translation of Proper Nouns. This is an arduous task in Translation Studies to convey the main essence of the nouns amongst cultures. This is somehow due to the fact that every culture has its own system of rendering of proper nouns. Longman Dictionary of Language Teaching and Applied Linguistics (Richards \& Schmidt, 2002, p.429) defines the proper name as "a name which is the name of a particular person, place, or thing. Proper nouns have disparate allusions such as age, sex, specific connotations, and geographical regions. This study scrutinized two major translations of Animal Farm of George Orwell. The first rendering is pertained to Amirshahi (2010) and the second one Firuzbakht (1988). Finally, this study seeks to investigate the translation procedures of proper nouns in accordance with Newmark and Vermeer's (Skopos) theories of translation. This study shows that Newmark mostly peruses proper noun artificially to saturate the taste of the reader. While, Vermeer sets up the mutual agreement between the reader as the client and the translator in this process.
\end{abstract}

Keywords: Translation of Proper Nouns, culture, Animal Farm of George Orwell, translation procedures, Newmark and Vermeer's (Skopos) theories of Translation

\section{Introduction}

\subsection{A Brief Talk on Orwell's Work}

George Orwellisa is a novelist, a journalist, an essayist, a literary critic, a political author and an infrequent poet and a man whose influence on his contemporaries is sharp and visible. He was born in India in 1903 and died, because of a lung ailment, in England in 1950. George Orwell is pen name attributed to him; he had been christened Eric Blair. He is a writer of great force and distinction. Perhaps he would be reminded others of only as journalist and critic. But, in fact, the story is far more; John Atkins, the author of a critical study of Orwell, says(" his uniqueness lays in his having the mind of an intellectual and the feeling of a common man").Orwell, thus, is a dynamic, many sided, man (Richard H.Rovere 1956).

Orwell sharply hated two things; the first one was inequality and the latter political lying. To him, these two things violated "democratic socialism". He "thought of exposing the soviet myth" in a story that could be easily understood by almost anyone and which could be translated into other languages. He retells one of his experiences when he was in England and what was happening out there (Ball 1929).

Orwell had seen socialist ideal in action and in fact the destruction of which by non-natural enemies, communists on the left. All these was a burden on him, in the middle of world war II, therefore he put aside his job on BBC and began Animal Farm, a work of fable written in November 1943. A fable is a kind of narration to strengthen a practical truth. Fables have two features; firstly they teach a moral lesson and the characters are mostly animals. These animals most often function as a satiric device to exhibit the foolishness of humankind. In this respect, as Susan McHugh says, we are dealing with animal studies. She mentions that the symbolic value of Orwell's character not only guide people in learning important events in human history but sharpen their critical minds to get deeper meanings (McHugh 2009).However Animal farm is written on many levels, one of which is to look it over as a kind of fiction.

Animal Farmis is an anti-utopian fiction, "a kind of fiction which shows man at a mercy of a purpose over which he has no control". The nineteenth century particularly was interested in the idea of utopia, not only in literature, but also in social experiment. Men in nineteen century believed in the viability of the perfectibility of mankind, a time all men would live together in a united world and under a peaceful circumstance. But in twenty century this very belief has been undermined. Wars, hot and cold ones, follow each other; revolution and civil war clouded the atmosphere of a better future. So, "not man perfected but man perverted", this is what dystopian fiction wants to reveal. Orwell thus writes for the people and the readers of western democracy to remind them this fact and shows how false the dominant idea of soviet Russian as a socialist state is. Actually he wants to save socialism from communism (Allen and Thompson 1993). 
Generally speaking, proper names encompass several categories: names of persons, animals, companies, geographical places, sign sand festivals. Nevertheless, it makes difference in which situation they are going to be examined. In real life, proper nouns are considered meaningless and only they are used for signaling references. It just serves a denotative purpose and according to Nord (2003) "proper names may be non-descriptive, but they are obviously not noninformative". As an example, if the name "john" is considered, there is nothing essential in itself and therefore it is in accordance with the abovementioned definition. However, Nord adds "if we are familiar with the culture in question..." Proper names can make us aware of gender, age, geographical origin. People think that these nouns are untranslatable; Vendler (1975) writes that proper nouns are untranslatable, but in the process of translation we can carry them over. However, after we compare translation of source texts (ST) with their target texts (TTs) we take this fact that they have used a wide variety of strategies dealing with them: the use of particular names, meaningful names, interpretation of names, text effects they produce, etc. According to Hermans, proper nouns "occupy an exceptional position with regard to language system because of their minimal integration to it" (1988, p.12). Thus special consideration should be taken into account in translating of such materials.

Tymoczko (1999, p.223) also asserts that proper names are indicative of "racial, ethnic, national and religious identity". In addition, she explains that these names are "dense signifier" and they are problematic in translation because they are dependent on "cultural paradigms". It is basically accepted that a text based on its culturally specific items would be foreignized or domesticated discussed by many different scholars.

Last but not least, the proper nouns in Animal farm are well suited to standard of living of every ilk of people and this study wants to investigate the closeness of proper nouns in the source and target language. It can be stated that translation nowadays is a multidisciplinary field and one must aware the function of materials such as proper nouns, rites, cultures of the source and target language in order that he or she will convey the near essence of the source language. Proper nouns are culture-based and it is the art of the translator to transfer the content of the intended material into the target text. As Nord (2003, p.82) points out that just a quick look in translator's work can bring this notion that translator has done everything with names. In this regard, concerning the translation of name, scholars embody the issue of culture-specific items which are barely successful to convey these cultural patterns (Aixela'1996; Tymoczko 1999; and Davis 2003). Therefore it is the task of translator to take a lot of consideration into account in these non-trivial and challenging elements to find a good solution. Proper nouns are not just restricted to the name of the people. While it covers the vast range of materials such as flora, fauna, social district issue, etc. Therefore, preparing ourselves in dealing with kinds of situation is of great importance. Appropriate rendition of proper nouns makes the cultures homogenized. The people then can perceive each other suitably and then they will better understand of their cultures. So, it must be better that the translator works on the cultural homogenization rather he or she depicts the differences or hierarchy of languages.

\subsection{Significance of the Study}

This study is more significant for some groups such as translators and language learners for several reasons:

1. The first and the most important reason is that translator becomes aware of strategies used in translation of proper nouns and in fact bridging the gap between linguistic context and situational ones.

2. The second reason is to show translators how to cope with translations of such elements and giving guidelines to make the best choice, so far as possible, in this area.

3. Translation of proper nouns, considering different aspect of study, is based on a purpose. Clients, therefore, are given directions how to decide a work to be translated in terms of the intended purpose.

\subsection{Definition of Terms}

The following terms, as frequently discussed throughout the study, are defined as follow:

\subsubsection{Proper Noun}

There are lots of definitions given by different scholars with regard to proper noun. However, they have the same nature. The Merriam-Webster (2009) defines that a proper name is "a word or group of words (such as "Noah Webster," "Kentucky," or "U.S. Congress") that is the name of a particular person, place, or thing and that usually begins with a capital letter". Also other scholars like Alexander (1988) indicate that a proper noun (sometimes a proper name) is use for a particular person, place, object or idea which is unique (p.38).

\subsubsection{Skopos Theory}

The Skopos theory was developed by Hans Vermeer. One of the important factors in this context is the function which the translation is supposed to fulfill in the target culture and it is the very function which Reiss and Vermeer (1984) have focused on. According to which translation, as a "translatorial action", is determined by its purpose, technically referred to it by the Greek term Skopos. So the determining factor in translation is not the source text or source situation, but the Skopos of the target text in the target situation. Thus translation is defined as the process of producing a text which is "functionally adequate" in the target situation. Since the Skopos theory of the target is in some way a function of the target reader, therefore the Skopos theory of the target text can be different from that of the source text, and the same source text can be translated in different ways based on the needs and conditions of the target reader. 


\subsubsection{Proper Noun and Newark's Theory}

Newark (1998) in his A Textbook of translation takes his examples from three classes of proper noun: people's name, names of objects, and geographical names. As he says, first name and last name of people normally are transferred, providing that there is no connotation in the text, by which their nationality is maintained. Yet in some cases a proper name may be translated, as with Popes, Saints, or with names which connotations are palpable in imaginative literature. However, mostly classical names are naturalized, that is to say, transformed to normal language pronunciation and spelling- some scholars refer to it as transliteration: 'Horace' in English for 'Horatius' in Latin, for example. Where both nationality and connotation is of utmost importance, naturalization along with translation should be employed. For instance, in Tolstoy's Resurrection, where the name 'Nabatov'-alluding to an alarm condition- is changed into 'Alarmove'. Objects' names are usually transferred, including brands, trademarks and proprietaries. In terms of geographical names we should look for correspondent in atlas or a similar source. $\mathrm{He}$, in the end, adds that we have to tell some context from others in which toponyms occur: an item in an address it will be transferred, but the same as cultural scenery in a brochure, for instance, it will, to some extent, be translated.

\section{Review of Literature}

Generally speaking, proper noun alludes to several categories: name of people such as hypocorisms, pseudonyms, animal, name of institution, geographical zones, astronomic signs, and name of particular ceremonies in this connection. Every translator utilizes some special techniques to deal with proper nouns in the source text. The definition of "proper noun" in The Oxford Concise English Dictionary would be: a proper name is "a name for an individual person, place, or organization having an initial capital letter" (2001, p.1146). It then adds: "if we are familiar with the culture in question, a proper name can tell us whether the referent is a female or a male person, may be even about their age, (some people name their new born child after the pop star or a character of the film.......) or their geographical origin within the same language community........ " (2003, p.183). For translating proper nouns into target language, the translator always should consider that "How can be possible to saturate the taste of audience?" According to Nord (2003, p.183), proper nouns may be non-descriptive, but they are obviously not non-informative. This means that, the translator cannot claim to render every proper noun in every situation. The most important factor in rendering proper noun will be to pay attention to "decoding ability ${ }^{1}$ (Eugene Nida, 1964)." It should be noted that, child in decoding ability plays the most important role amongst others. Whenever a translator can be able to saturate the taste of child at early age, he or she can transmit the main content of the text to other ilk in decoding ability. Maria Tymoczko (1999, p.223) also indicates that proper nouns can be categorized into: ethnic, racial, national, and religious identity. She then alludes to proper nouns as "dense signifiers" which they are "the most problematic to translate, in part because their [...] significance is often culturally specific and dependent on cultural paradigms" (1999, p.223-4). In this connection, Aixelá expounds proper nouns "“account for the greatest percentage of the culturally specific items in a text” (Aixelá cited in Tymoczko, 1999, p.240). Culture in general, is the indispensible part of proper nouns to render. In this regard, cultural diversification is of great important to consider. The translator should be able to render in accordance with diverse geographical zones in order to convey the main essence of the source language to target audience. Later, Lincoln Fernandes explains that proper nouns are utilized as "dense signifiers in the sense that they contain in themselves clues about the destiny of a character or indicates of the way the storyline may develop" (Fernandes, 2006, p.46). According to Akbari (2013), Wafting $^{2}$ As a direct and intense translation process, it has a connection with render or even transfer as the original SL by inserting or absorbing the SL words or phrase form into the RL's, such as the rendering of proper names in translation. Proper names play an important role in a literary work. They point to the setting, social status and of other part of speech can go along with their nominal function carry out the function of characterizing a person or a place. In translating proper name for children, it is noticeable to render such words according to their taste. In this respect, children can depict the obvious picture of word and can easily connect themselves to the intended word. For example, "Rihanna" would be entered to Persian, German, and Italian Languages without any alteration via "Borrowing" process. Intermediacy model suggests using the nativized word as "Reihane" instead of "Rihanna". "Reihane" passed the filter of deep layer of wafting process and then nativized elegantly in order to convey the exact sense of the intended word. In rendering of the proper names, Maria Tymoczko (1999, p.224) states that "translators can "bring [...] the audience to the text" and transfer the name unchanged or "bring [...] the text to the audience" and adapt the name. Manini (1996, p.171) agrees that "translators can choose to leave all proper names [...] in their original form" and preserve the "otherness" or "they can $[\ldots]$ decide to translate those names" which have equivalents in the target language and make the text familiar to the readers." In some situations, the translator should concoct the equivalent of the intended word to saturate the needs of the audience due to the fact that the decoding ability can be able to connect him or herself to the target text. Therefore, Gergana Apostolova expresses that: The transformation of names in translation [...] is rooted deeply in the cultural background of the translator which includes phonetic and phonological competence, morphological competence, complete understanding of the context, correct attitude to the message, respect for tradition, compliance with the current state of cross-cultural interference of languages, respect for the cultural values and the responsibilities of the translator. The process reaches from an ear for aesthetic sounding to the philosophical motivation of re-naming (2004, p.14).

\section{Methodology}

The analytical part is based on one English original book, animal farm, and two translations of which provided in Persian. One of them has been translated by Amir Amirshahi in 2010 and the latter has been translated by Mohammad Firuzbakht in 1988. These two translations have been chosen randomly among the large number of translations of the 
intended book existed in library. However, by investigating the proper nouns in these two translations it comes to the point that the first one is moving toward the author and the second translation is moving toward the reader considering no border or redlines in this direction. In other words, we have foreignization in the first case and domestication in the other one, respectively. The reason for choosing these two rendering will be the first translation is the updated one and the latter is old-dated one. The authors of this article want to know the workability of proper nouns in saturating the taste of the reader in general. Two kinds of translations with two different sights are one of the key materials in this article. But the most important factor will be to utilize the correct translation of the intended materials. And then, some proper nouns were extracted by the two rendering of Animal Farm. Finally, the extracted proper nouns are scrutinized by two challenging theories such as and Skopos theory in Translation Studies. Newmark's theory deals with the transference of the proper nouns. While Skopos theory emphasizes the mutual agreement amongst the source and target languages, the translator, and the client and then concentrates on the role of client as the prime importance. Each example is perused correctly to see of any similarities and discrepancies in rendering the proper nouns.

\section{Data analysis}

In this section, this paper seeks to investigate on range on equivalences proposed by Mohammad Firuzbakht and Amir Amirshahi. Both translations were analyzed based on two dominant models in translation studies. Newmark (1988) and Vermeer (1992) have given their prescriptions and according to which the two translations being analyzed. When being analyzed, it becomes clear that in these two cases the age of translations was not inefficient. The more the recent, the more the adequate translation will be in terms of proper names. It is, nevertheless, not a sufficient criterion in proving the betterment of translation. With these descriptions, there are a lot of translations reveal the otherwise situation. In this study, proper names are categorized as particular proper noun (PPN) and general proper noun (GPN). Particular proper nouns refer to the names of people and countries which are used in target locale and they are specifically defined. And general proper nouns refer to names of particular places and objects in the target Language and they are not restricted to some special features of the source language. They are generically defined. This typological-referenced work can be useful and helpful for the act of translator.

\subsection{Particular Proper Nouns}

PPN alludes to the name of the people, flora, fauna, organizations, and etc. this group is the most sensitive group in that it should be rendered correctly to convey the main sense of the word into the target language. Sometimes, the abovementioned group inclines to culture-specific words, therefore; it can be stated that it is vehemently tied with culture.
ST: Mr. Johns
TT1: Aqaye Johns (Johns)
TT2: Aqaye Johns (Johns)

One of the best feature best renderings is to preserve the local color of ST. But, to what extent the renderer can be able to go? In translation field, the renderer should depict the red line for him or herself in order to transfer the main sense of the intended word. According to Newmark (1988), the translator should transfer the local color of the source language word. It should be noted that, before translating the text, the renderer should consider the genre of the text to convey the near meaning of the source language to the target one. In this direction, if the translator will find hi or herself in the sitcom position, he or she can translate the above-mentioned word as "Aqa Yahya". But, the genre of "Animal Farm" would be completely political and the translator should render exactly. Another note will be that the translator should not repeat the intended word either Farsi or English. Repetition causes the creation of dense translation and will not be acceptable in the target language. According to Skopos theory, translation seeks three purposes in translation: (1) Recreation of the target word, (2) Representation, and (3) Reproduction. Therefore, in translating the above-mentioned word, the renderer should consider the role of purpose and the role of the audience in the text. Thus "Aqaye Johns" with repeating element of the word will be better understood by the target reader. Both of the translations utilize the same technique which is completely rudimental. Therefore, it is better to eliminate the English part and then resort to transliteration of the source language.

$$
\text { ST: Old Major }
$$

TT1: Majere Pir

TT2: Majere Pir

There are often problem with the rendering of the physical behavior equivalence. In this direction, Newmark (1988, p82) expressed that "in principle, such words should first be translated, with if necessary, the transferred word and the functional equivalence added in brackets, till you are confident that your readership recognizes and understands such words." Therefore, it can be stated that, in rendering the above-mentioned word, the translator should not utilize the semi-culture translation for which the target reader cannot be able to connect him/herself to the target one and it cause the creation of artificial translation. In this connection, Skopos theory expressed that all names should be scrutinized by their functions in the sentence. One to one correspondence or natural equivalence are against Skopos theory in that they pay more attention to the source language and does not consider the target audience either. It should be stated that repetition technique in translation will not be acceptable and make dense rendering of the text. Therefore, as it is possible; translation should be to the point and terse. Brevity is an asset in rendering of the text naturally. 


ST: England TT1: No translation $\quad$ TT2:Engelestan

Translators in terms of their methods use their strategies; some are in fond of foreignization but some other lean toward domestication nevertheless. The first translator has not translated the intended word. That is why in such a case translator cannot domesticate the foreign word. Accordingly, he inevitably should omit the word in a way that removes the color of the original. In this case the renderer "leave the reader in peace, as much as possible, and moves the author toward him' (Schleiermacher, 1813/2004, p.49). This act of translator in fact is not moving toward domestication, but this is in fact foreignizing the context of the text. On the basis of Newmark model, as discussed before, geographical names are usually transferred. The second translation is in line with the model and in this context this procedure is acceptable. In this direction, Skopos defines translation in terms of a new function or the same function. Thus, the latter function would be a good choice for making in this situation. To clarify more on "Same function" Nord (1997, p.18) depicted one diagram in which it expounded cross cultural communication:

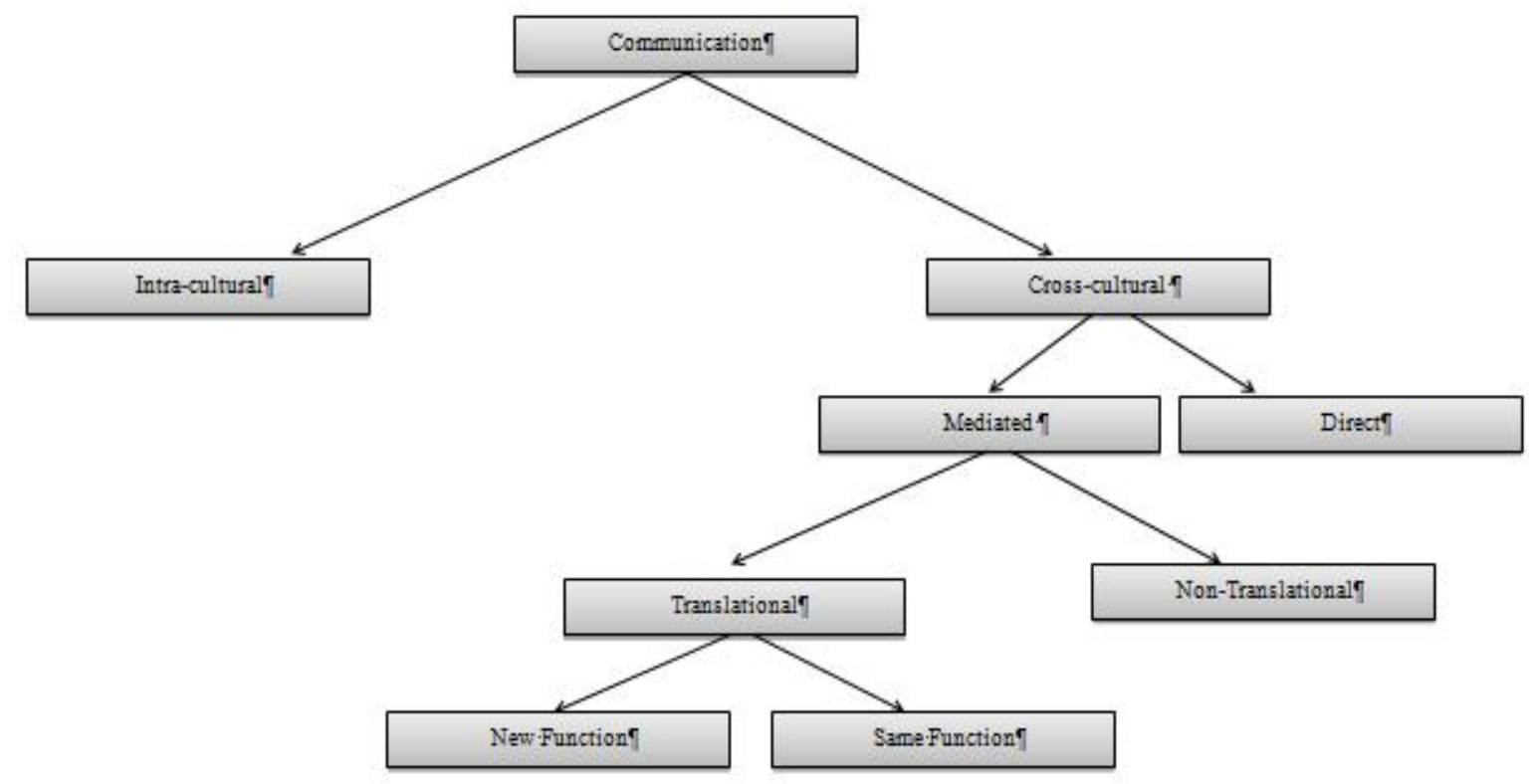

Same function in this diagram alludes to one to one correspondence of equivalent. According to Nord (1997) documentary translation works with literal, word for word, or exoticizing rendering in the target text. Whenever the translator sees him or herself into the deadlock, he or she can utilize from the above-mentioned strategies. But, using same function in the target language is not absolute license to covey the exact sense of the source text in particular. Totally, the translator will better to render all of the parts of the text. Therefore, the second translation will be highly praised in accordance with the Newmark's theory.

\begin{tabular}{lll}
\hline ST: Brussels Carpet & TT1:Farsh & TT2:Ghalihaye Kare Bruxel \\
\hline
\end{tabular}

Rendering in this part, also the previous part, corresponds with partial translation that is one part is to be translated and the next one is to be transferred (Catford 1965, p.21-22)). The first translator has used generalization in this case and has put the foreign word, Brussels, aside. It is clear that the translator is inclined to domestication and virtually avoids foreignization as far as possible. But, the second translator is the otherwise. On the basis of Newmark model, he has utilized transference. However, one of the most significant outcomes of purpose-driven paradigm is that translator can increase or decrease the information in the source text if so needed, in other words, the renderer can make the implicit information explicit. This case is obvious in the second rendering (TT2). Skopos theory knows the purpose of translator is described by the individual translator, that is, we have an expert in socio-cultural communication and we cannot define "good" or "bad" translation in this respect. If we do so, we just are changing the descriptive position to the prescriptive one (Pym, 2010, p.56-9). Consequently, it should be stated that the translator should be faithful to the source language text. In this rendering, the first translator just transfers the superficial content of the source, while the latter rendering simulates the source language in the target one to convey the specific traits of the source proper noun.

One of the features of proper noun therefore is having initial capital letter. However, some names, per se, are general names but the author changes those general names into special ones by adding capital letter to the initial part or in a new sense, making a proper name. Authors use such a strategy in order to accentuate some nouns more than others. Our translators, in this case, have used their own strategies. The first one has translated literally and the second one has used 
a kind of generalization which can be considered as non-translation. It is clear that neither the first nor the second translator has conveyed the intended meaning. A simple suggestion can be that the words should be written in bold to maintain a kind of effect that readers could think of them in the process of reading. So, in this case the Newmark model cannot work properly but the other model which is based on the Skopos theory of the target text can work appropriately.
ST: Willington Beauty
TT1: Esme Zibaye Willington
TT2: Esme Zibaye Willington

In rendering such particular proper nouns, the translator must consider the target reader in first case. Sometimes, translators render several words being completely dazzling and hard to perceive. In this connection, the bystander will not be able to perceive the sense of the text which is Newmark called "vogue words" (Newmark, 1998, p 82). It is the beauty of translator's work to clarify every sense of the text thoroughly and make it ready to utilize in the target language. Therefore, in approving the above-mentioned expound, Skopos (cited in Pym, 2010, p. 50) “when a message has to cross into another culture, the people sending that message will require help from an expert in cross cultural communication." Nowadays, translation resistance is of great importance in the target culture. How can translator be sure about his or her right equivalent in the target language in order not to see any language resistancy by the target reader? How will it be possible to institutionalize the equivalents in TL? The only solution will be to utilize natural or nativized wafting in the target language. Akbari (2013) expressed that "A word can be naturalized wafting when it can be naturalized to fit the spelling rules in the Target Language (TL). Naturalized wafting will be any kind of wafting process in which the intended word wafts partially or totally but naturally transforms the main essence of the intended word. This wafting process applies both frequency and intensity of the word to carry the exact theme of the word. In this direction, naturalized wafting is sometime pertained or inclined to partial wafting and sometimes to total wafting (Akbari, 2013, p. 22)." Last but not least, translator cannot break the borders amongst the source and target completely and he or she should respect the reader. It is better to say, in rendering the renderer should ordain the red line and apply or devise the equivalents in red line environment.

\subsection{General Proper Noun}

This category refers to general name in the source and the target language. For instance, name of the human behavior, daily routines, and the rite of people. In this group, the translator should reduce the effect or intensification of the source text into the target language in order to generalize the rendering. The most sensitive group in this category will be children and adults. This category does not consider culture completely and it applies every rendering superficially.

In both rendering, the translators utilize the technique of "reduction" sense of the source language. In the Persian language, the rite and heritage of the intended language do not break some pre-determined law. One of these rites in translation will be to render the name of alcoholic drinks. The translator render as such because they deal with children and adult and these term are vehemently culture bound. But, Newmark (1998) expressed that "cultural words are often transferred to give local color, to attract reader, and to give the sense of intimacy between the text and the reader." This quotation annulled the red line environment that the translator should obey during translating the text. It is better for translator to utilize the technique of compensation in order to reduce the harm and pernicious effects of the intended word. It should be noted that, Skopos theory expressed that the translator can be able to translate covert meaning of the word but he or she cannot deal with the overt meaning of the words easily and the translator should translate indirectly in some situations in order to amalgamate the reader and the translation altogether. It is completely natural to see that whenever the reader perceives some element against his or her creeds, he or she shuns keeping on the text in this connection. Skopos theory pays much attention to the role of client in the target language. In Islamic countries, imbibing alcoholic drinks regard as taboo. Therefore, in this situation; the translator should tone down the specificity of the intended word.

\begin{tabular}{cll}
\hline ST: Sugar candy & TT1: No translation & TT2:Mistranslation \\
\hline
\end{tabular}

Renderer, most often, when translating geographical names, names of different places encounter a dilemma; that's why they don't know whether translate the intended word or leaving it alone. With respect to this problem, Newmark (1988, p.82) gives an adequate suggestion: "geographical and topographical names including new independent countries such as (le) Zaire, Malawi, unless they already have recognized translations", they all "normally transferred". However, Skopos theory maneuvers in better open space. This theory asserts that a source text can have different target texts based on different purposes. With all these, both model complement each other and in fact open a new way for renderer to make his/her sensible choice. Mistranslation is one of the traps which sometimes translator utilizes in the translation. That is because of lack of context or knowledge of the translator. Skopos emphasizes red line in translation. The translator should ordain the red line which he should pass this line. Passing this red line equals to untranslatability or mistranslatilbility. 
Sometimes, choosing an acceptable equivalent in translation of general proper noun (GPN) becomes a difficult task. When our proper name is a central name and on which the story is revolving around, actually the renderer cannot translate the minor names like that of the major ones which are the gist of the fiction. Newmark (1988) introduces another type of shift where "literal translation is grammatically possible but may not accord with natural usage in the TL". The mentioned-quotation corresponds with the second translation (TT2) in which the Arabic suffix used is not acceptable for Persian native reader. In his respect, Vinay and Darbelnet (1965) in their direct translation introduces borrowing strategy when there is no way for translation. But, here we have a kind of par-borrowing, adding Arabic suffix ("yat"), technique which doesn't work well here. On the other side, Vermeer gives much notice to Skopos (purpose) of the text and this view pulls him toward radicalism with respect to the function of the target text. But, maintaining the function should not be to the extent that affects the target text negatively. And it is proper to say that the first renderer (TT1) has produced an adequate equivalent by considering the text, co-text, and the situation in which it has been occurred.

\section{ST: Meeting}

TT1:Miting

TT2:Jalase

Both translators have used different strategies of translation. The first translator has utilized naturalization, that is, bringing the word to the context of target text and thus making the pronunciation and word-form as normal as possible, in fact it is what Newmark(1988) points out. The second translator uses semantic translation. In this regard, Newmark (1981, p.39) suggests that "semantic translation attempts to render, as closely as the semantic and syntactic structures of the second language allow, the exact contextual meaning of the original". Semantic translation of Newmark resembles Nida's formal equivalence. However, it is not acceptable for Newmark to have the full principle of equivalent effect, because this effect does not work well out of TL situation, space and time. In some way, Skopos matters that this naturalization and maintenance of the word is supposed to be what Skopos is intended to fulfill, i.e., the client's commission. Taking all into consideration, we can mention that both translations are acceptable in target text context. Each acts on the basis of the intended purpose of translator or renderer.

\begin{tabular}{lll}
\hline ST: Windsor's chair $\quad$ TT1:Sandaliye Rahati & TT2: Sandaliye Chubiye Dastedar
\end{tabular}

Translators are looking for equivalence which can yield a good and fruitful translation, however they should be aware of the illusion of this interpretive function (Robinson, 1991, p.259-89). Both translators have used the functional-based, in accordance with the Skopos theory. The first one has used generalization in the second part of the word to make the situation easier for the target reader. On the other side, the second translator is looking for a proper equivalence for the intended proper noun. Therefore he goes through explicitation. Newmark (1988, p.83), in this direction, hardly accept functional equivalent except for special cases: "functional cultural equivalent are even more restricted in translation, but they may occasionally be used if the term is of little importance in a popular article or popular fiction." In these two translation, the translators use natural equivalence to show their faithfulness in translation. But, in Translation Studies; transferring the sense is of great importance. Therefore, the translator first should make a paradigm of his or her translation, and then he or she must be faithful in rendering. Both of the renderings will be acceptable in that they consider the role of decoding ability in the target language.

$$
\text { ST: Manor Farm }
$$

TT1: Mazraeye Manor

TT2: Mazraeye Manor

One of the most common strategies renderers use when translating proper names is transference; perhaps that's why it is the easiest and more justifiable than other techniques. In both cases, translators have used transference strategy and both added the English version in parenthesis as a kind of compensation strategy. Adding or deleting the intended parenthesis makes no difference for the reader since a foreign word for the reader is a foreign word. Readers take it as an unknown name but he/she has this presupposition that as the text progresses, they can have a better understanding of that name. In the same line, the Skopos theory can come to terms with transference, based on the commission. Therefore, Skopos theory model can include Newmark model, but the otherwise cannot occur.

\begin{tabular}{cll}
\hline ST1:Donkey & TT1:Kharha & TT2:Kharha \\
\hline
\end{tabular}

Sometimes general names are changed into proper names in the process of writing. It means that the author makes those particular proper nouns. Characters carry different characteristic and become dynamic as the story goes on. And also characters can remain simple and naive and become flat as it becomes obvious as the text reveals. Authors use some strategies to make some nouns distinctive and to attach some distinguishing qualities or traits to characters in order to make that character dynamic. In other words, the author changes a general noun into particular proper noun. Thus, we are dealing with different purposes of the author and also different goals of the text. In such a text, because the text is 
purpose-driven, the commission would be a multi-oriented commission. So, it is the Skopos theory model that can play a significant role in resolving the problem. And Translators, both of them, have not paid attention to such meticulous manner of the author.

\section{Discussion}

Proper nouns behave in a non-trivial ways in translation. Proper names, like other linguistic expressions, deal with a host of meanings. That is, the structure of their meaning is basically like that of other kinds of expressions. It is of utmost significance that the status of proper nouns is the function of that particular context; in this regard, dealing with pragmatic is unavoidable. Thus the treatment of these names is as complex as other expressions. As to clarify the point, attention should be paid to the levels that the intended book, Animal farm, has been written. The story can be scrutinized as a political, a satirical and an allegorical or even as children work. Therefore, if we consider it as political, it would fundamentally be different from taking the story as a children work. In this direction the function of text and accordingly the choices made by the translator for translation should be different.

In this study, we are investigating proper nouns in term of two models, Newmark and the Skopos. Newmark model describes three ways so as to transfer proper names into target language: transference, translation, and naturalization. And the Skopos model is revolving around the function of the project, commission from the client, and "dethroning" the original materials. Although the framework of the study was theoretical, the inference of which would be clear that the translation involves the translator in a multi-dimensional transaction of information which extends from the source author to the audience. In a general sense, one of the most important things a translator should not forget is that the aim of interaction is toward the reader. With all these, there are various descriptive-typological approaches that all are insufficient in providing a complete and consistent translation phenomena, however, these two models, like others, are adequate ones in opening new ways and showing guidelines along which the translator can move.

\section{Conclusion}

This study sought to investigate on proper nouns translation ins and outs. Two topmost models were scrutinized in this study: (1) Newmark Theory of Translation of communicative and semantic approach in Translation Studies and (2) Vermeer's theory known as Skopos theory of translation. The former was trying to build up the transference process of proper nouns and did not pay attention to the deep layer of meaning of Proper nouns in general and always perused superficial meaning in order to saturate the taste of audience. And the latter, it would pay attention to the third party known as "Client". In all of the instances he expounded, Vermeer wanted to depict client as the first factor and the role of translator as second factor. Proper Nouns are culture-based and it is an arduous task for the translator to convey the same impression into the target language. Therefore, he or she should create the same situation in the target language in order to convince the reader. In this regard, cultural homogenization will be an asset in Translation Studies. So, the renderer first should design a paradigm of proper nouns generically, and then makes it to specific cases to transfer the main essence of the text. It should be noted that the translator should consider the taste of the reader prior the act of translation. One of the important factors in proper nouns analysis will be decoding ability. The type of audience will be of greater importance for the translator. The translator acts as a bridge to connect every ilk of people. Therefore, creating the same situation in these two theories in order to saturate the needs of the reader are emphasized. To cut a long story shorts, translation of proper nouns is of great importance in TS. It is better to sat that translation should be done in a way which is completely understandable either in source language or target one.

\section{Reference}

Aixelá, J. F. (1996) “Culture-specific Items in Translation”, in R. Álvarez and M. C.-Á. Vidal (eds.) Translation Power Subversion, 8, 52-78, Clevedon: Multilingual Matters.

Akbari, A. R. (2013). Exploring into the New Model Procedure in Translation: Wafting as a Case in Point, International Journal of Education and Literary Studies, 1, 19-20. Doi: 10.7575/aiac.ijels.v.1n.2p.18, http://dx.doi.org/10.7575/aiac.ijels.v.1n.2p.18

Allen, D., L. (1993). Cliff note on Orwell's Animal farm.Barchester Towers: C.K.Hillegass, 7-10.

Catford, J.C. (1965). A Linguistic Theory of Translation. London: Oxford University Press, 21-2.

Davison, P. (1996). George Orwell A Literary life. New York: MacMillan press LTD.

Davies, E. E. (2003) “A Goblin or a Dirty Nose? The Treatment of Culture-Specific References in Translations of the Harry Potter Books”, The Translator 9(1): 65-100.

Hermans, Th. (1988) “On Translating Proper Names, with reference to De Witte and Max Havelaar”, in M.J. Wintle (ed.) Modern Dutch Studies. Essays in Honour of ProfessorPeter King on the Occasion of his Retirement, 1-24, London/Atlantic Highlands: The Athlone Press.

McHugh S.(2009).Animal Farm's Lessons for Literary (and) Animal Studies.Humanimalia: a journal of human/animal interface studies, 1(1), 24-25.

Newmark, P.. (1988). Textbook of Translation. U. K: Prentice Hall, 81-93.

Nida, E. A. (1964). Towards a Science of Translating. Leiden: E. J. Brill, 156-171. 
Nord, C,.(2003). Proper Names in Translation for Children: Alice in Wonderland as a Case in Point. Meta, 48 (1-2), pp.182-194.

Nord, C. (1997). Translating as Purposeful Activity. Functionalist Approaches Explained, Manchester: St. Jerome Publication, 18.

Orwell, G. (1956). The Orwell Reader. New York: Harcourt, Brace and World, Inc., ix-xiii.

... (2010). Animal farm. Translated from English by Amir Amirshahi in 2010. Tehran: Jami publication.

... (2010). Animal farm. Translated from English by Mohammad Firuzbakht in 1988. Tehran: Golshaie publication.

Pym, A. (2010).Exploring translation Theories. New York/London: Routledge, 56-9.

Richards J C. and R. Schmidt. (2002).Longman Dictionary of Language Teaching and Applied Linguistics, 429.

Robinson, D. (1991). The Translator's Turn. Baltimore, Md.: Johns Hopkins University, 259-89.

Schleiermacher, F. (1813/1992)'on the different methods of translating', in L. Venuti (ed.) (2004), 43-63.

Tymoczko, M. (1999). Translation in a Postcolonial Context. Manchester: St Jerome, 223-4, 240.

Vendler, Z. (1975). 'Singular Terms'. In Steinberg and Jakobovits (eds.), 115-133.

Vermeer, H. J. (1992). Skopos und Translationsauftrag - Aufsätze.Frankfurt am Main: IKO-Verlag.

Vinay, J. and J.C. Darbelnet, (1965) Stylistiquecomparie du francaiset de Vanglais. Paris:Didier, 58.

Webster, M. (2009). Merriam Webster Collegiate Dictionary

\section{Notes}

1. Decoding ability in any language involves at least four principal levels: (1) the capacity of children whose vocabulary and cultural experience are limited. (2) The double standard of capacity of new literates, who can decode oral message with facility but whose ability to decode written message is limited. (3) the capacity of average literate adult, who can handle both oral and written messages with relative ease; and (4) the unusually high capacity of specialists (doctors, theologians, philosophers, scientists, etc.), when they are decoding messages within their own area specialization.

2.Wafting As a direct and intense translation process, it has a connection with render or even transfer as the original SL by inserting or absorbing the SL words or phrase form into the RL's in accordance to prestigious, frequency and intensity of the intended word.

\section{Appendix}

Here is the English and Persian pilot appendices utilized during this study:

\section{CHAPTER 1}

Mr. Jones, of the Manor Farm, had locked the hen-houses for the night, but was too drunk to remember to shut the popholes. With the ring of light from his lantern dancing from side to side, he lurched across the yard, kicked off his boots at the back door, drew himself a last glass of beer from the barrel in the scullery, and made his way up to bed, where Mrs. Jones was already snoring.

As soon as the light in the bedroom went out there was a stirring and a fluttering all through the farm buildings. Word had gone round during the day that old Major, the prize Middle White boar, had had a strange dream on the previous night and wished to communicate it to the other animals. It had been agreed that they should all meet in the big barn as soon as Mr. Jones was safely out of the way. Old Major (so he was always called, though the name under which he had been exhibited was Willingdon Beauty) was so highly regarded on the farm that everyone was quite ready to lose an hour's sleep in order to hear what he had to say.

\section{Chapter 3}

When asked whether he was not happier now that Jones was gone, he would say only "Donkeys live a long time. None of you has ever seen a dead donkey," and the others had to be content with this cryptic answer.

On Sundays there was no work. Breakfast was an hour later than usual and after breakfast there was a ceremony which was observed every week without fail. First came the hoisting of the flag. Snowball had found in the harness-room an old green tablecloth of Mrs. Jones's and had painted on it a hoof and a horn in white. This was run up the flagstaff in the farmhouse garden every Sunday morning. The flag was green, Snowball explained, to represent the green fields of England, while the hoof and horn signified the future Republic of the Animals which would arise when the human race had been finally overthrown. After the hoisting of the flag all the animals trooped into the big barn for a general assembly which was known as the Meeting. Here the work of the coming week was planned out and resolutions were put forward and debated. It was always the pigs who put forward the resolutions. The other animals understood how to vote, but could never think of any resolutions of their own. 
(Amirshahi) فصل

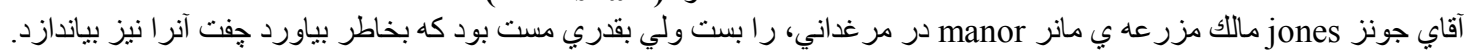

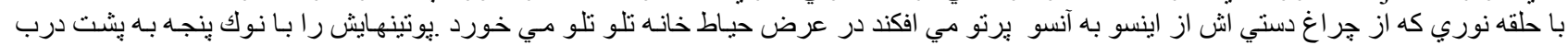

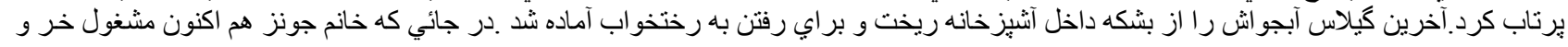

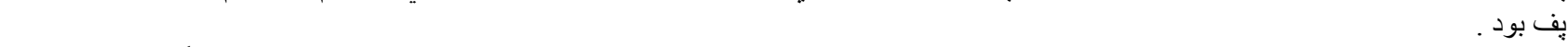

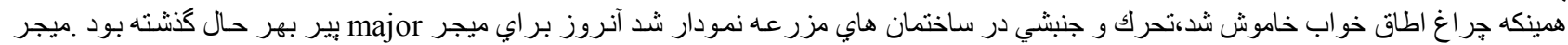

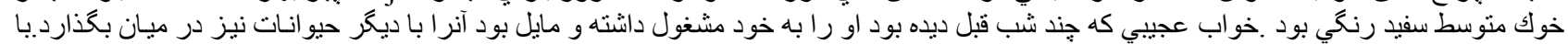

فصل اول(Firuzbakht)

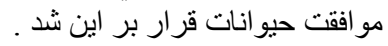

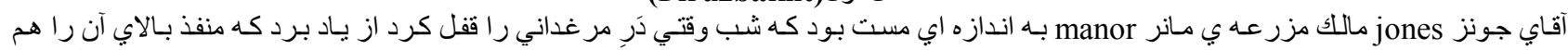

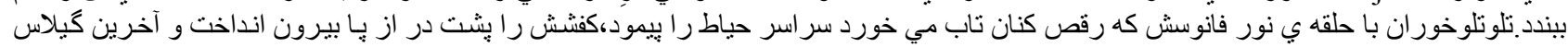

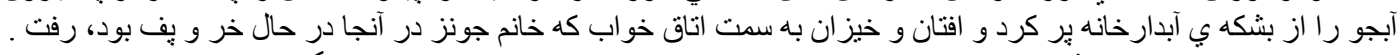

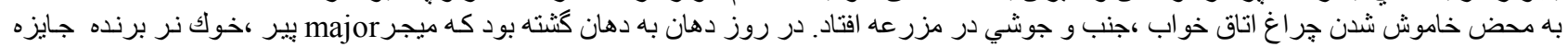

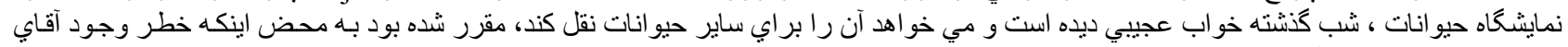

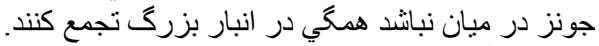

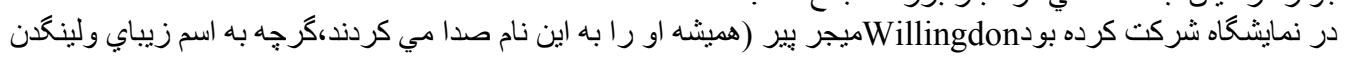

(Amirshahi)

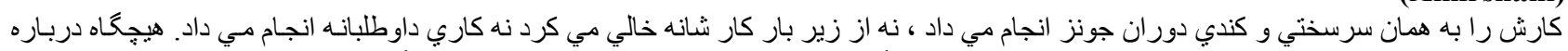

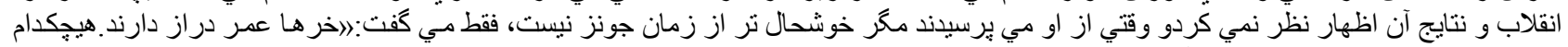

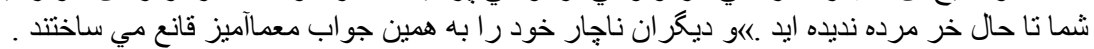

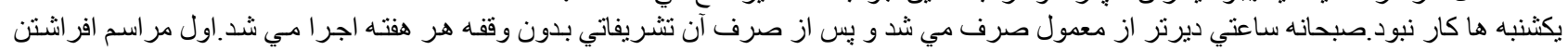

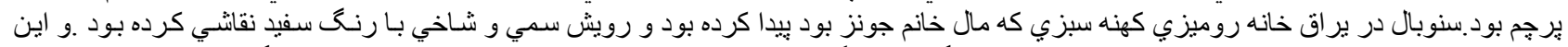

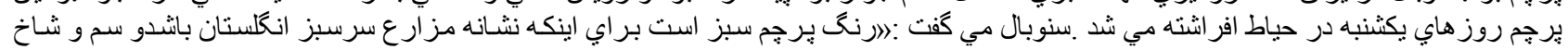

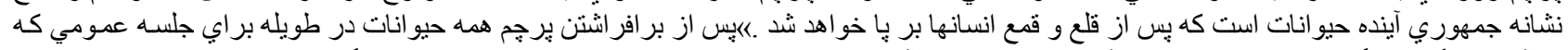

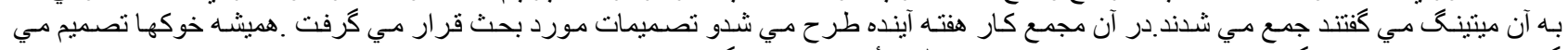

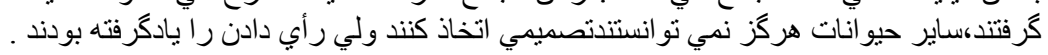

(Firuzbakht)

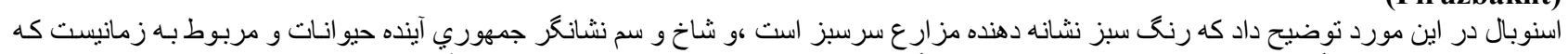

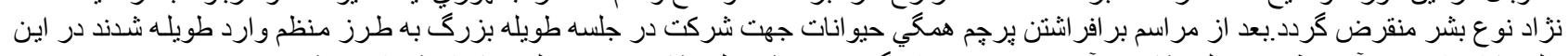

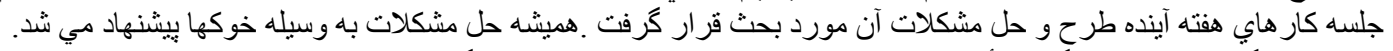

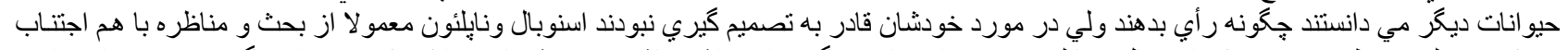

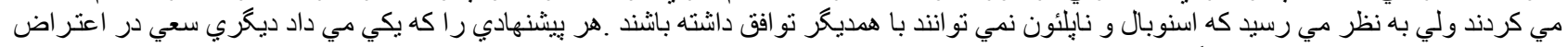

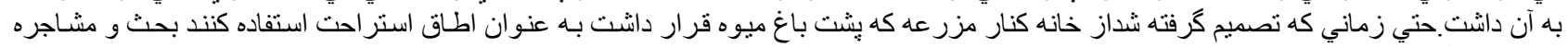

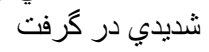

